\title{
A doença, católica em particular
}

\author{
Giovanni Levi \\ Tradução: Sérgio Lamarão
}

1. Enquanto eu escrevia estas linhas, um discurso proferido pelo papa Bento XVI, em Ratisbona, em 12 de setembro de 2006, provocou grande repercussão. Porém, como é frequente o caso quando as notícias passam pelo filtro dos jornais, foi apenas sobre a parte referente à crítica da doutrina corânica deste texto importante que se lançou o foco. Muitos outros aspectos foram rapidamente esquecidos, ao menos para a opinião pública. O discurso do papa apresenta, no entanto, e de forma clara, alguns dos sinais da doença católica, e não dos menos significativos: uma volta atrás em relação ao Vaticano II, no que diz respeito à doutrina, e, no que concerne à política para com as outras fés religiosas, o retorno à situação anterior a João Paulo II. Voltarei a alguns desses aspectos para esclarecer uma das doenças cristãs, aquela que mais repercute politicamente nos países católicos. Se a ideia tinha sido falar da doença cristá, de modo genérico, nós precisaríamos voltar muito mais atrás e investigar, desde as origens, uma unidade cristã doente, o que teria sido se aventurar de um modo insensato. De resto, uma história bimilenar destruiu há muito e muito tempo essa unidade, desenvolvendo numerosos cristianismos. Trata-se, portanto, ao meu ver, antes de se interrogar com mais precisão sobre as razões profundas e específicas que levaram o mundo cristão a se fraturar em numerosas religiôes, distintas e antagônicas. Falarei aqui de uma dessas razões: a relação entre vida religiosa e vida política enquanto causa fundamental das expressões díspares que o cristianismo assume nos mundos católico, protestante e ortodoxo.

Vejamos, pois, algumas coisas que foram ditas em Ratisbona pelo papa Ratzinger, por ocasião do seu discurso "Fé, razão e universidade. Lembranças e reflexões".

O documento afirma que há, no catolicismo, uma fusão entre a razão da tradição grega e a fé da tradição cristã, e polemiza contra aqueles que sustentam que "Deus é absolutamente transcendente" e que "Sua vontade não está ligada a nenhuma das nossas categorias, incluindo a da razoabilidade". E acrescenta: "Começou com Dans Escoto a teoria do voluntarismo que, em seus desdobramentos posteriores, havia de levar à afirmação segundo a qual, de Deus, só conheceremos a voluntas ordinata [...], posições que podem ser aproximadas às de Ibn Hazm e tender para a imagem de um Deus-Árbitro, que não está mais ligado nem à verdade nem ao bem”. Não é difícil perceber, por detrás dessas imagens, uma polêmica não somente com o Islã, mas também com todas as concepções que apresentam Deus como imperscrutável, ${ }^{2}$ na tradição judaica, ou ainda na tradição protestante do Deus absconditus. $\mathrm{O}$ ataque mais explícito, no entanto, é aquele dirigido contra o Islã, através de uma citação do imperador bizantino Manuel II Paleólogo, que disse o seguinte ao erudito persa com quem travava uma discussão: "Mostrame o que Maomé trouxe de novo. Apenas encontrarás coisas más e desumanas, como a sua diretiva de espalhar com a espada a fé que pregava”. A edição da $7^{a}$ Controvérsia citada pelo papa é a de Théodore Khoury. ${ }^{3}$ Khoury - em uma longa introdução, caracterizada por uma descrição condescendente e anistórica do cristianismo, grosseiramente antijudaica e anti-islâmica, uma vez que apresenta como características destas religiōes seus aspectos mais criticáveis (poligamia, talião etc.) - deixa claro, no entanto, que o Islã em nenhum momento sustenta que a fé possa ser imposta pela violência. É essa referência do papa que assume a tese do imperador como se esta fosse uma característica efetivamente própria ao Islâ, que suscitou a justa cólera dos fiéis desta religião. Um outro elemento merece ser sublinhado. O diálogo entre Manuel e o erudito persa se desenrola em 1391. Nesse ano, tem início na Espanha a grande perseguição antijudaica, que incluiu, entre outros, os pogroms de Girona e as violências praticadas contra os judeus para obrigá-los a se converter ao cristianismo. Nesse exato momento - em 1391, nem um ano antes, nem um ano depois -, quando o imperador acusava falsamente os muçulmanos de utilizar 
a violência na conversão dos infiéis, os cristãos espanhóis convertiam para sempre os judeus pela força. Eu me pergunto se o papa entregou-se voluntariamente a essa curiosa manipulação ou se foi seu inconsciente que repetiu uma operação encontrada com muita frequência na elaboração ideológica de um cristianismo nascido, ele próprio, de uma oposição simbólica à tradição judaica: esquecer uma realidade histórica que mostra os cristãos como culpados para melhor utilizá-la, voltando-a contra outros.

Assim, o papa Ratzinger chega à conclusão eurocêntrica de que "não é de se espantar que o cristianismo, apesar da suas origens e de alguns desenvolvimentos importantes no Oriente, tenha encontrado a sua fisionomia decisiva na Europa. (...) O encontro [entre a fé bíblica e o questionamento filosófico grego] criou a Europa e permanece o fundamento daquilo que, com razão, se pode chamar Europa”. Ele polemiza, em seguida, com todas as teses que visam à des-helenização do cristianismo, isto é, todas as teorias que pretendem retornar a uma fé pura e originária, que diminui o papel da tradição interpretativa e mediadora da Igreja: “(...) a sola scriptura busca a figura primordial da fé (...). Kant procedeu, fundado neste programa, afirmando que teve de pôr de lado o pensar para poder dar espaço à fé. Foi assim que ele ancorou a fé exclusivamente na razão prática, negando-lhe o acesso ao conjunto da realidade”.

Trata-se, portanto, de uma doença particular do cristianismo à qual eu gostaria de falar aqui, sublinhando, ao mesmo tempo, as implicações políticas e a capacidade de criar uma antropologia específica, ela mesma suscetível de dar conta de muitos traços característicos dos países católicos. Doença que encontra sua origem no fato de que o catolicismo é o único a possuir uma estrutura hierárquica centralizada, um governo absoluto, uma tradição estatal, e que, portanto, somente o cristianismo é capaz de entrar efetivamente em competição com as realidades políticas que foram criadas no curso da formação dos Estados modernos. Essa é a razão pela qual me parece importante partir da virada que está em vias de acontecer sob os nossos olhos na política de um protagonista deste calibre dos acontecimentos que estão por vir, uma virada eurocêntrica e combativa para com as outras religiōes monoteístas, a começar pelo Islã. O catolicismo é a única religião cujo chefe absoluto tem o poder de propor e de realizar uma política específica em nome de mais de um bilhão de homens.

2. Há, por conseguinte, numerosas maneiras de se chegar a Deus. Por conta disso, há implicações culturais diferentes, presentes no ponto de vista da interiorização dos princípios normativos que daí derivam, mesmo que Freud tenha falado de uma forma muito geral da relação entre religião e explicação racional da condição humana.

Em O futuro de uma ilusão, a psicanálise defronta-se com o problema da civilização e também com a história política da Europa, debruçando-se sobre o desenvolvimento passado da civilização e vislumbrando um futuro no qual a religião verá o seu papel ilusório declinar. Assim, as normas morais são fundadas numa crença que não é necessariamente um erro, mas antes uma ilusão, visto que o que prevalece em sua motivação é a satisfação dos antigos desejos que fazem abstração da relação com a realidade. A religião pode nos falar, e nós falamos, sobre determinados aspectos do desenvolvimento da civilização mais do que a história pode provar. Ilusão não significa ausência de valor histórico: "O reconhecimento do valor histórico que algumas doutrinas religiosas encerram aumenta o respeito que nós lhes conferimos, mas não invalida nossa proposição de excluí-las da motivação das exigências culturais" . ${ }^{4}$ Em uma palavra, Freud afirma que já é tempo de "substituir as consequências da repressão pelos resultados do trabalho mental racional", 5 reconciliando os homens com a civilização, mas renunciando à verdade histórica: "Não se deve lamentar o fato de que, ao aceitarmos a motivação racional das exigências culturais, renunciamos à verdade histórica. As verdades que as doutrinas religiosas contêm são tão deformadas e sistematicamente disfarçadas que o conjunto dos homens não saberia reconhecer nelas a verdade."

Freud descreveu o papel da fé em Deus como oposto ao simples fundamento social enquanto base das interdições culturais que constituem a civilização, colocando ênfase na sucessão ou na alternativa, segundo os lugares e os tempos, e não na superposição, no mesmo momento e no mesmo país, nem na ambiguidade entre sistemas normativos coexistentes. Através da religião - é Freud quem fala -, nós não 
colocamos em dia o fundamento racional das proibições - no caso, aqui, a proibição do homicídio -, mas afirmamos que foi Deus que a promulgou:

Ao agirmos assim, revestimos a interdição cultural com uma solenidade toda particular, mas corremos o risco, igualmente, de fazer depender sua observância da crença em Deus. Se anulamos essa iniciativa, se não atribuímos mais a Deus nosso próprio querer e contentamo-nos em basear a interdição cultural em móveis sociais, certamente renunciamos, por isso, à sua natureza sagrada, mas também a livramos de um perigo. Há ainda uma outra vantagem. Por uma espécie de difusão, de infecção, o caráter do sagrado, do inviolável, do além, poder-se-ia dizer, estendeu-se de algumas poucas interdições importantes para todas as outras instituiçōes, leis e disposições culturais. E a auréola quase sempre não é assentada nelas; não apenas elas se anulam reciprocamente uma à outra, editando medidas contraditórias conforme os tempos e os lugares, como também trazem ainda todas as marcas da imperfeição humana. Pode-se facilmente distinguir entre elas aquela que é engendrada por crenças de visão curta, aquela que é a expressão de interesses mesquinhos e aquela que resulta de premissas inadequadas. A crítica à qual obrigou-se a submetê-las diminui, em proporçôes lamentáveis, o respeito devido a outras exigências culturais mais bem justificadas. Como se trata de uma tarefa delicada julgar o que o próprio Deus ordenou e o que emana da autoridade de um Parlamento todo-poderoso ou de um magistrado supremo, haveria uma indubitável vantagem em deixar Deus completamente fora da questão e confessar honestamente a origem puramente humana de todas as instituições e prescrições da cultura. Ao mesmo tempo que sua pretensão a uma origem sagrada cairia por terra, cessariam também a rigidez e a imutabilidade destas leis e disposições. Os homens seriam instados a comprender que estas foram criadas bem menos para controlá-los do que em seu próprio interesse, e teriam para com elas uma atitude mais amigável, e ao invés de aboli-las, visariam somente aperfeiçoá-las. ${ }^{7}$

Por conseguinte, temos um discurso geral sobre a crença, e não sobre uma religião específica, mesmo se as referências parecem ser, no essencial, ao cristianismo, salvo para aquilo que é uma breve alusão ao povo eleito. Se se quer agora entrar na complexidade dos cristianismos, a pena de Freud coloca um problema, que continua, em essência, sem solução - talvez ele seja insolúvel - para aquilo que concerne à tradição cristã. Quando a religião se torna política, quando sai da esfera privada para se ocupar das instituições civis, cria-se um dualismo inegável com as leis que emanam dos poderes civis. Dualismo que está na base - por causa da impossibilidade, justamente, de se levar em conta o que pertence a Deus e o que pertence a César - de uma conflitualidade de fundo, que perdura no domínio político público, bem como na esfera íntima das consciências individuais.

3. Para Freud, a religião desempenhou um papel fundamental na interiorização da coerção externa que nos foi imposta pelas coerções da pulsão, necessárias à civilização. Este "reforço do superego" é um "progresso psíquico", "de acordo com a nossa evolução": é um "patrimônio psicológico de alto valor para a cultura". ${ }^{8}$ Entretanto, ele apagou progressivamente o elemento de verdade histórica que tinha contribuído para revelar aos homens, mediante a introdução de deformações e de disfarces sistemáticos que fizeram dos dogmas religiosos uma espécie de "sobrevivências neuróticas", que devem ser substituídas pelo trabalho racional.

Eu dizia que, curiosamente, Freud não se colocou a questão da copresença - que não é a da alternância no tempo ou na hierarquia - de duas instâncias coercitivas paralelas e, sob muitos aspectos, contraditórias: a da religião e a do Estado. Toda a história política do Estado moderno é feita, porém, do conflito entre dois sistemas normativos que ditam regras não coerentes entre elas. Conflito que teve e pode ainda ter saídas muito diferentes, segundo as relações entre os dois sistemas no interior da criação daquilo que poderíamos chamar de "as antropologias políticas de hoje”, as atitudes dos cidadãos para com as instituiçôes. Um superego fortalecido, ou enfraquecido, segundo a maneira pela qual uma "instância psíquica particular, o superego do homem, toma a seu encargo" ${ }^{10}$ as normas contraditórias que este sistema normativo dual impõe.

Portanto, nós partimos de longe para afirmar que toda a história ocidental - a história do cristianismo, ou melhor, dos cristianismos - assistiu constantemente ao confronto de duas hipóteses intrinseca- 
mente diferentes sobre a relação entre religião e Estado. O conflito foi coagulado no momento da Reforma protestante em uma oposição significativa.

Permitam-me simplificar em muito para ir ao essencial: no decorrer do século XVI, a Europa se dividiu em duas. Para o mundo protestante, foi Deus quem criou o poder e - malgrado uma evolução complexa que levará a teorias absolutistas e também a teorias constitucionais - a sacralidade do poder conserva sempre uma forte significação.

Uma vez perdida a consciência de sua origem teológica, resta uma antropologia específica na qual o respeito às instituições desempenham um papel importante, tanto para o melhor quanto para o pior, estando as instituições religiosas de algum modo hierarquizadas em relação à sacralidade implícita no poder político. Nas teorias protestantes, o debate se desenvolverá em torno da questão de saber qual é o poder criado por Deus, se é o do príncipe ou o dos magistrados em geral, ou ainda o do povo, que, inspirado por Deus, elege seus representantes. Porém, o halo de sacralidade que cerca o poder permanece progressivamente interiorizado enquanto valor civil, numa atitude de reconhecimento positivo e respeitoso das instituições políticas. Naturalmente, não há nisso senão implicações positivas: tanto a história do totalitarismo de Estado quanto a do constitucionalismo democrático mergulham suas raízes num produto histórico que frequentemente esqueceu suas origens teológicas, sem, concretamente, ter se distanciado delas tanto assim. Isso deu nascimento a numerosas e diferentes formas políticas, que vão da obediência absoluta ao poder - mesmo se ímpio, porque enviado por Deus para punição dos nossos pecados, como sustentará Lutero até outubro de 1530 - ao dever de resistir ao príncipe ímpio através dos magistrados inferiores, ao direito democrático de resistir através dos éforos, representantes eleitos do povo. Todas essas configuraçōes, por mais diferentes que sejam, colocam o acento, em relação àquilo que se passa no mundo católico, no papel divino na definição das formas de governo: embora Deus tenha desaparecido, a sacralidade do poder persiste em profundidade. ${ }^{11}$

No que lhe concerne, o mundo católico construirá uma teoria política completamente diferente. Deus não tem responsabilidade nas instituições dos homens. Deus limitou-se à criação de seres sociais, que têm o dever, ou a necessidade, de se dedicar ao governo. Mas devido ao nosso livre arbítrio, acabamos criando as instituições que nós queremos - relinquantur humano arbitrio, diz Tomás de Aquino. ${ }^{12}$ Todavia, os homens são pecadores, eles se darão sempre instituições imperfeitas, daí a necessidade de que a Igreja esteja presente, com o encargo de criticar e corrigir as instituiçôes dos homens para conduzi-las, progressivamente, ao longo do caminho da salvação. Elaborada com o renascimento do tomismo no século XVI e reafirmada no decorrer da gestação e do desenvolvimento do concílio de Trento, esta posição torna-se dominante no pensameto político católico, em particular através da formulação límpida que lhe dá o jesuíta Francisco Suarez em seu Legibus ac Deo legislator, elaborado de 1582 a 1612, mas cujos elementos são pouco a pouco definidos nos escritos de Dominique Soto, François de Victoria, Roberto Bellarmino e outros teólogos dominicanos e jesuítas. Cria-se, dessa maneira, uma outra antropologia, na qual não há nem hierarquização nem divisão nítida dos domínios, mas sim copresença das duas autoridades em luta pela supremacia e pela definição de seus campos de competências respectivos, que se confundem e se superpõem continuamente, com regras e princípios muitas vezes contraditórios. Antropologia caracterizada pela fraqueza das instituições e pelo poder conferido pela prática do perdão, da remissão das penas, da incerteza jurídica. Aqui, também, a religião talvez seja doravante reprimida, mas, sob a secularização aparente, 400 anos de copresença deram forma a um sentido político e a um sentido da justiça dominados pelo dualismo. No mundo católico, haverá também, naturalmente, soluçôes diferenciadas, à mercê dos conflitos e dos compromissos seculares entre o Estado e a Igreja, tendo, entretanto, por base comum o enfraquecimento do sistema institucional como consequência da presença de dois sistemas normativos não coerentes, e tendo por corolário frequente a proliferação normativa típica dos Estados frágeis, incapazes de obter um consenso pleno. 
4. Examinemos, pois, o dualismo. É preciso relembrar que certos defensores do catolicismo mais esclarecido vêem no dualismo um antídoto ao excesso de poder estatal e um fundamento da liberdade, mesmo se é difícil não deixar de pensar no grande número de ditadores que as sociedades católicas produziram. Minha interpretação é diferente: o dualismo fragiliza o sistema político. A autonomia laica aparente do campo político, confiado totalmente à arbitragem humana, só seria positiva se fosse acompanhada da condição de tutorado implícita que configura a presença da Igreja como árbitro último de uma sociedade de pecadores e da ambiguidade de regras emitidas por duas autoridades diferentes. $\mathrm{Na}$ doutrina católica, os homens não recebem a soberania de Deus, porque apenas a Igreja é soberana nesse sentido. A fim de examinar a questão em detalhe, citarei aqui um outro texto importante de Joseph Ratzinger, escrito quando ele ainda não era o pontífice, retirado do livro de Paolo Prodi, Christianisme et monde moderne. ${ }^{13}$ Minha perspectiva será muito diferente da do autor, que vê justamente no dualismo o fundamento da liberdade, ainda que criticando o papel político que a Igreja assumiu desde o século XVI até os nossos dias, misturando a realidade temporal de um Estado, o Estado da Igreja, e a realidade espiritual de uma religião universal.

Partindo de Mateus, 22, 21 - "Dai a César o que é de César, dai a Deus o que é de Deus", aquele que é então o cardeal Ratzinger escreve:

Esta afirmação de Jesus quebrou qualquer forma de identificação entre as pretensões dos Estados para com os homens e a exigência sacra da vontade divina para com o mundo (...) É precisamente esta separação das autoridades sacra e estatal, assim como o novo dualismo da qual ela era portadora, que representa o ponto de partida e o fundamento persistente da ideia ocidental de liberdade, já que a partir daí existem duas comunidades reciprocamente ordenadas, mas não idênticas, não usufruindo, nenhuma delas, do caráter de totalidade. ${ }^{14}$

Até aqui, ao menos na aparência, o equilíbrio entre as duas autoridades parece remeter a campos diferentes, definidos e delimitados. Mas a imagem muda muito rapidamente:

O Estado não é mais, ele mesmo, portador de uma autoridade religiosa, (...) mesmo se, devido ao seu fundamento ético, remete, além dele mesmo, a uma outra comunidade. Esta outra comunidade, a Igreja, compreende a si mesma como uma última instância ética, que se baseia, entretanto, no pertencimento voluntário e pode infringir puniçôes unicamente espirituais e não civis. (...) A liberdade se baseia no equilíbrio recíproco destas duas ordens. ${ }^{15}$

A liberdade constitui, portanto, a última instância dos princípios éticos do Estado, como se fosse possível separar completamente princípios jurídicos e princípios éticos e como se fosse possível fazer coincidir completamente o ético e o sagrado, o que aparece no trecho que se segue:

A condição fundamental da liberdade encontra-se somente lá, onde está preservado o dualismo da Igreja e do Estado, que estabelece a distância entre o sagrado e o político. Lá onde a Igreja se torna, ela mesma, Estado, a liberdade está perdida. Mas também é verdade que lá, onde a Igreja é suprimida enquanto instância pública e publicamente pertinente, a liberdade desaparece porque lá o Estado, de novo, reivindica a fundação da ética como sua. ${ }^{16}$

Assim, a distinção confusa entre ética e política deveria definir dois campos separáveis e separados. Para não deixar subsistir nenhum equívoco, Ratzinger acrescenta: "Nós definimos assim o dever fundamental da sociedade eclesiástica (...) Ela deve visar a conservação do equilíbrio de um sistema dual que seja fundamento da liberdade. É por isso que a Igreja deve estabelecer exigências frente ao direito público e não mais simplesmente se recolher ao quadro do direito privado" ${ }^{17}$ Ao invadir o campo do direito público, a Igreja não se dirige somente às consciências individuais: é o campo político que ela invade.

A Igreja tem, naturalmente, o direito de apoiar o que julga ser justo apoiar. Gostaria de sublinhar, porém, que a teorização desta posição, que implica a presença de duas autoridades diferentes no campo político - o que Ratzinger chama de "direito público" -, não implica a divisão entre a fé enquanto fato privado e a política, mas a copresença dual de duas fontes normativas no mesmo campo. Quanto 
a nós, temos, sem dúvida, exorcizado e esquecido este princípio, mas no mundo católico o princípio se afirmou no curso dos séculos e foi progressivamente interiorizado, a ponto de criar uma concepção específica da política, incapaz de operar uma separação verdadeira entre política e religião, ou uma hierarquização e uma definição de seus campos de pertinência.

Como procurei demonstrar, a religião pouco a pouco transformou-se em uma antropologia política. O que nós interiorizamos, além dos aspectos mais estreitamente ligados à fé na existência de Deus, são atitudes que se refletem no comportamento que adotamos na sociedade, em nossas atitudes políticas e em nosso sentido de justiça. A doença cristã de hoje tem mais de um rosto e numerosas e diferentes consequências, a começar por uma divisão nítida da Europa e do Ocidente. Em uma palavra, há mais de uma versão da doença cristã. A diferença maior reside, na minha opinião, em uma história diferente da capacidade de hierarquizar (não de subordinar) Estado e religião. A França, desde Luís XVI, viu reafirmar a sacralidade do poder real e a subordinação parcial da Igreja aos princípios éticos autônomos do Estado, o que faz dela um país repleto de católicos, mas não um país católico. Já a Itália, e isso é característico, não foi capaz de resolver o problema. Daí um anarquismo católico difuso - retomo aqui a definição de Bartolomé Clavero ${ }^{18}$-, uma desconfiança generalizada para com as instituições públicas e uma representação contratual da relação com a religião, oscilando entre pecado e perdão, poder daqueles que perdoam, fraqueza daqueles que pecam.

Tudo isso tem ainda outras consequências. Em um momento em que o conflito entre religiōes se manifesta de forma particular pelo confronto entre o Ocidente e o Islã, a doença cristã, em sua expressão católica, corre o risco de divulgar posições, conscientes e inconscientes, de uma profunda gravidade. Parece-me que não se pode limitar a questão da religião a um conflito entre razão e ilusão, mas sim que é preciso ver em aspectos específicos da política católica uma evolução perigosa em direção à intolerância. Jan Asseman ${ }^{19}$ pôde afirmar que a invenção do monoteísmo foi acompanhada da emergência da intolerância e não é difícil ver, nas muitas ocasiões recentes em que o catolicismo se manifestou - os exemplos evocados acima me parecem que confirmam isso -, uma pretensão à supremacia, mesmo se essa pretensão esteja mascarada por detrás da tela da aliança entre religiōes contra a negação da religião.

5. Não cabe ao historiador que eu sou julgar o efeito do dualismo ambíguo das autoridades normativas das quais falo sobre a construção do supergo nas sociedades católicas. A organização neurótica em torno da nostalgia infantil de um pai protetor todo-poderoso tem, provavelmente, efeitos específicos que remetem não apenas à vida psíquica individual, mas também à estrutura das relações entre os sexos, à das relações familiares e intergeracionais. Ao mesmo tempo, a relação enfraquecida com as instituições e a própria Igreja determina uma mentalidade intersticial e transformista, feita de compromisso, de indulgência, de astúcia, de erros. E de perdão. Uma sociedade na qual gerar o perdão em nome de Deus confere um poder substancial é uma sociedade que pode recusar, ilusoriamente, como se ela não existisse, a impureza enquanto corpo estranho a ser completamente excluído. Trata-se de uma questão de dosagem nas atitudes diferentes dos católicos e dos outros cristãos. Doença incurável, portanto, e de modo algum em fase terminal.

\section{Notas}

${ }^{1}$ Osservatore Romano, 13 de setembro de 2006. Nós recorremos ao texto em francês em sua versão definitiva, revista e anotada pelo próprio papa, tal como aparece no site www.generation.benoitxvi.com.

${ }^{2} \mathrm{Ou}$, em linguagem corrente, inescrutável.

${ }^{3}$ Th. Khoury. Man uel II Paléologue, Entretiens avec un Musulman, 7e Controverse. Éditions du Cerf, 1966.

${ }^{4}$ FREUD, Sigmund. L’Avenir d'une illusion (1927), traduzido do alemão por M. Bonaparte, PUF, 1980, p. 62. Esse texto foi traduzido para o português como $O$ futuro de uma ilusão e publicado, juntamente com $O$ mal-estar na civilização, no volume XXI das obras completas de Freud, lançado pela editora Imago, do Rio de Janeiro, em 1986. 
${ }^{5}$ Ibid.

${ }^{6}$ Ibid., p. 63.

${ }^{7}$ Ibid., pp. 58-59.

${ }^{8}$ Ibid., p. 17.

${ }^{9}$ Ibid., p. 62.

${ }^{10}$ Ibid., p. 17.

${ }^{11}$ Cf. Q. Skinner, The foundations of modern political thought. The age of reformation. Cambridge: Cambridge University Press, 1978.

12 Tomás de Aquino, Summa theologica, Prima secundae, questio 108, articulus secundus, note 3.

${ }^{13}$ P. Prodi, Christianisme et monde moderne. Paris: Le Seuil, 2006.

${ }^{14}$ J. Ratzinger, Kirche, Okumene und Politik. Neue Versuche zur Ekklesiologie. Einsiedeln, Johannes, 1987, pp. 155-157, citado por P. Prodi, op. cit., pp. 218-220.

15 Ibid.

16 Ibid.

${ }^{17}$ Ibid.

${ }^{18}$ B. Clavero, Antídoto, Antropologia cattolica de la economia moderna. Milão: Giuffré, 1999.

${ }^{19} \mathrm{~J}$. Assemam, Das kulturelle Gedachtnis. Schrift, Erinnenung und politische identitat in fruhen Hochkulturen. C. H. Beck'sche Verlagsbuchhandlung. Munique, 1992;

\section{RESUMO}

A análise do discurso do papa Bento XVI, de setembro de 2006, permite perceber, de forma clara, alguns sinais da atual doença católica: o retrocesso ao periodo anterior ao Vaticano II, em relação à doutrina e à politica relativa às demais crenças religiosas. A fratura do mundo cristão em numerosas religiōes, distintas e antagônicas explica em parte essa doença, cujas origens encontram-se na relação entre vida religiosa e vida politica enquanto causa fundamental das expressoes desiguais que o cristianismo assume nos mundos católico, protestante e ortodoxo. Trata-se, portanto, de uma doença particular do cristianismo; doença que encontra seu começo no fato de que o catolicismo é o único a possuir uma estrutura hierárquica centralizada, um governo absoluto, uma tradição estatal, e que, portanto, somente o cristianismo é capaz de competir com as realidades politicas que foram criadas no curso da formação dos Estados modernos. Palavras-chave: cristianismos; Bento XVI; catolicismo europeu; religião e estado.

\footnotetext{
ABSTRACT

The analysis of Pope Benedict XVI speech, in September 2006, lets see, clearly, some signs of present Catholic illness: the regression to the period before the Second Vatican Council, concerning to doctrine and policy on other religious beliefs. The fracture of the Christian world in many religions, distinct and antagonistic, partly explains the disease. Their origins lie in the relationship between religious life and political life as a fundamental cause of the unequal Christianity interpretation in the worlds Catholic, Protestant and Orthodox. It is therefore a particular disease of Christianity; it starts in the fact that Roman Catholicism is the only one to have a centralized hierarchical structure, an absolute government and a state tradition. Only Christianity would be able to compete with the political realities that were created during the formation of modern states.

Keywords: Christianity; Pope Benedict XVI; European Catholicism; religion and state.
} 